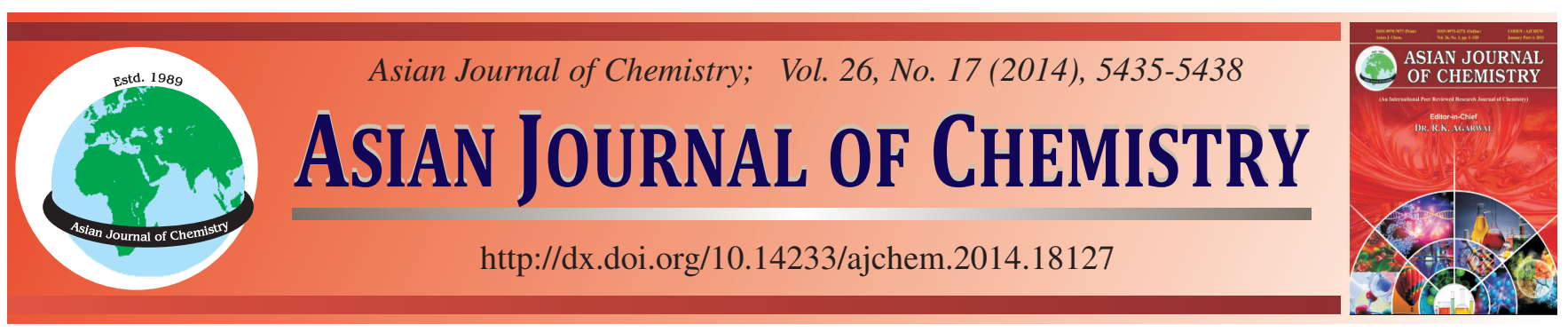

\title{
Application of Al-Doped SiC High Emissivity Powder Material Based on Infrared Radiating Coating $\dagger$
}

\begin{abstract}
Jun LiU ${ }^{1, *}$, Yong $\operatorname{Li}^{2}$ and JiANGTAO $\mathrm{Li}^{2}$
${ }^{1}$ Department of Mechanical Engineering, Foshan University, Foshan 528000, P.R. China

${ }^{2}$ Technical Institute of Physics and Chemistry, Chinese Academy of Sciences, Beijing 100080, P.R. China

*Corresponding author: E-mail: fsliujunfs@163.com

Combustion synthesis technology was used to prepare an Al-doped SiC infrared radiating ceramic powder material. The material's microstructure was analyzed by XRD, TEM and an IRE-2 infrared emitting ability survey meter. The relationship between the powder's architectural feature and the infrared radiating performance was obtained. According to the results, the $\mathrm{Al}$ atom enters the intracell by replacing a silicon atom and forms a structure of finite replacement-type solid solution, which results in an expansion of the SiC lattice parameter that consequently forms multiple structural defects, distorts the lattice and improves the emissivity. Furthermore, we found that the powder's normal emissivity in the scope of $8-12 \mu \mathrm{m}$ can reach 0.99 . Finally, the powder's application to infrared heating coating is discussed.

Keywords: Combustion synthesis, Infrared radiating coating, SiC lattice, Emissivity.
\end{abstract}

\section{INTRODUCTION}

Infrared radiating material is a new type of photo-thermal conversion material which rises in response to the proper time and conditions as infrared technology develops. The material has high emissivity and photo-thermal conversion performance under room temperature and is, therefore, applicable to various fields, like military affairs, energy conservation, environmental protection, medical treatment and health care ${ }^{1,2}$. As a new type of energy-saving material, the high-temperature infrared radiating material is highly energy-efficient when applied to industrial furnaces. This material is primarily composed of a radiating powder binder and agglomerant and improves temperature uniformity by strengthening the radiant heat transfer in furnaces to improve the furnaces' thermal efficiency and product quality ${ }^{3}$.

The infrared radiation of the material is produced when the material's molecular vibrations lead to changes in dipole moment. According to the law of vibration symmetry, the more asymmetric that a molecular vibration is, the larger the change in the dipole moment will be and, correspondingly, the stronger the infrared radiation will be. Mixing existing radiating material is an important way of reducing the symmetry of materials and, therefore, improving the infrared radiant efficiency ${ }^{4}$.
Silicon carbide ( $\mathrm{SiC}$ ) is a radiating matrix with high emissivity, which is characterized by rapid heat conduction, a high melting point, high-temperature structural intensity, good heat stability and excellent wear-resisting property. Although $\mathrm{SiC}$ has high emissivity, it only possesses this property in a certain main wavelength coverage. In addition, when the temperature rises above $1300{ }^{\circ} \mathrm{C}$, then $\mathrm{SiC}$ will be oxidized easily.

The combustion synthesis technology that has developed in recent years is a new, cost-effective technique for preparing ceramic materials. Its advantages include energy conservation, high efficiency and low cost, etc. Nevertheless, the heat released by the $\mathrm{Si}-\mathrm{C}$ reaction is low and fails to realize combustion synthesis at room temperature. Thus, the combustion synthesis reaction can occur only when supplemental energy is supplied to the system. Therefore, a new research direction is drawing attention: mechanically-activated combustion synthesis. It this type of combustion synthesis a high-energy ball milling pretreatment for the reaction's raw materials is first carried out and once the reactant activity is improved, the combustion synthesis reaction is implemented. To date, using mechanical combustion synthesis technology to successfully composite many kinds of matters, like $\mathrm{NbC}, \mathrm{WC}, \mathrm{TiN}, \mathrm{CrN}$ and $\mathrm{TiC}$, has been reported in literature ${ }^{5}$. 
The combustion synthesis method adopted by this study uses $\mathrm{Al}$ as the doping source and utilizes graphite and silica powder as the raw materials. Al-doped $\mathrm{SiC}$ powder is prepared by using the combustion synthesis method under argon protection. Furthermore, methods like XRD, SEM and TEM are used to characterize the powder, such as its microstructure, phase and infrared radiation characteristic. Additionally, its application to infrared radiating coating is discussed.

\section{EXPERIMENTAL}

Preparation of Al-doped SiC powder: The raw materials are a silica powder with an average grain diameter of $20 \mu \mathrm{m}$ and $>99 \%$ purity and a carbon black with an average grain diameter of $40 \mu \mathrm{m}$ and $>99 \%$ purity, $\mathrm{Al}: \mathrm{Si}: \mathrm{C}$ are mixed at a mole ratio of $0: 1: 1,0.05: 0.95: 1$ and $0.1: 0.9: 1$, respectively. The doping source is an $\mathrm{Al}$ powder with an average grain diameter of $75 \mu \mathrm{m}$ and $\mathrm{a}>99 \%$ purity. Three samples of different proportions are expressed as $\mathrm{C}_{0}, \mathrm{C}_{1}$ and $\mathrm{C}_{3}$. A small amount of ethyl alcohol is added to the weighed powder. After they have been ground in a ball-milling pot for $2 \mathrm{~h}$, they are dried under a vacuum. The ball-milled powder is uniformly placed into a graphite crucible and the crucible is then put into a self-prepared combustion-synthesis reaction kettle, which is composed of two chambers. One of the chambers can be heated by a thermoelectric couple. First, all the air in the kettle will be pumped out and argon will be put in. Then, one chamber is heated by a thermoelectric couple to $1250{ }^{\circ} \mathrm{C}$ and finally, the crucible is pushed into a hot chamber from a cold one in order to trigger a combustion synthesis reaction.

Preparation of infrared heating coating: Prepared Aldoped $\mathrm{SiC}$ powder and organic silicon resin are mixed in a certain proportion. Then, a dispersing agent, anti-settling agent and cosolvent are added. After that they have been sheared and dispersed by a stirring dispersion machine for $0.5 \mathrm{~h}$ and scattered uniformly at a high speed, the infrared heating coating is obtained through filtration. Next, this prepared coating is painted on tinplates. After solidifying them at $200-250{ }^{\circ} \mathrm{C}$ for $1 \mathrm{~h}$, heat them to $600^{\circ} \mathrm{C}$ and maintain this temperature for $3 \mathrm{~h}$. After cooling them in the cold chamber, normal infrared emissivity of the coating is tested.

Characteristics and performance of samples: An XRD test was carried out on the samples using a D/MAX-IIIC Xray diffractometer made in Japan. The experimental conditions were the following: $\mathrm{Cu}(\mathrm{ka})$ radiation and a graphite monochromator; the (SEM) S-4300 scanning electron microscope (Hitachi, Japan) and transmission electron microscope (TEM) were used to analyze its microstructure and an IRE-1 infrared emissivity tester was used to test its infrared radiation characteristic.

\section{RESULTS AND DISCUSSION}

Infrared radiating performance: At room temperature, the normal infrared emissivities of the three samples, $\mathrm{C}_{0}, \mathrm{C}_{1}$ and $\mathrm{C}_{3}$, in the range of $8-12 \mu \mathrm{m}$ is $0.89,0.98$ and 0.99 . According to the results, a sample's infrared emissivity increases as the doping amount also increases. The dopping of $\mathrm{Al}$ improves the infrared radiating characteristic of $\mathrm{SiC}$ powder.
Structural characterization of Al-doped $\mathrm{SiC}$ powder: Fig. 1(a) is an XRD chart of samples with different doping amounts. For the sample $\mathrm{C}_{0}$, only the $3 \mathrm{C}-\mathrm{SiC}$ phase exists, which corresponding to JCPDS 29-1129 in the standard card. For samples $\mathrm{C}_{1}$ and $\mathrm{C}_{2}$, the $\mathrm{C}-\mathrm{SiC}$ and $4 \mathrm{H}-\mathrm{SiC}$ phases coexist. In addition, there are some $\mathrm{Al}_{4} \mathrm{SiC}_{4}$ phases in $\mathrm{C}_{2}$. In accordance with the strongest peak in the $\mathrm{C}_{1}$ and $\mathrm{C}_{2}$ charts, it is judged that $3 \mathrm{C}-\mathrm{SiC}$ phase content is greater than $90 \%$.
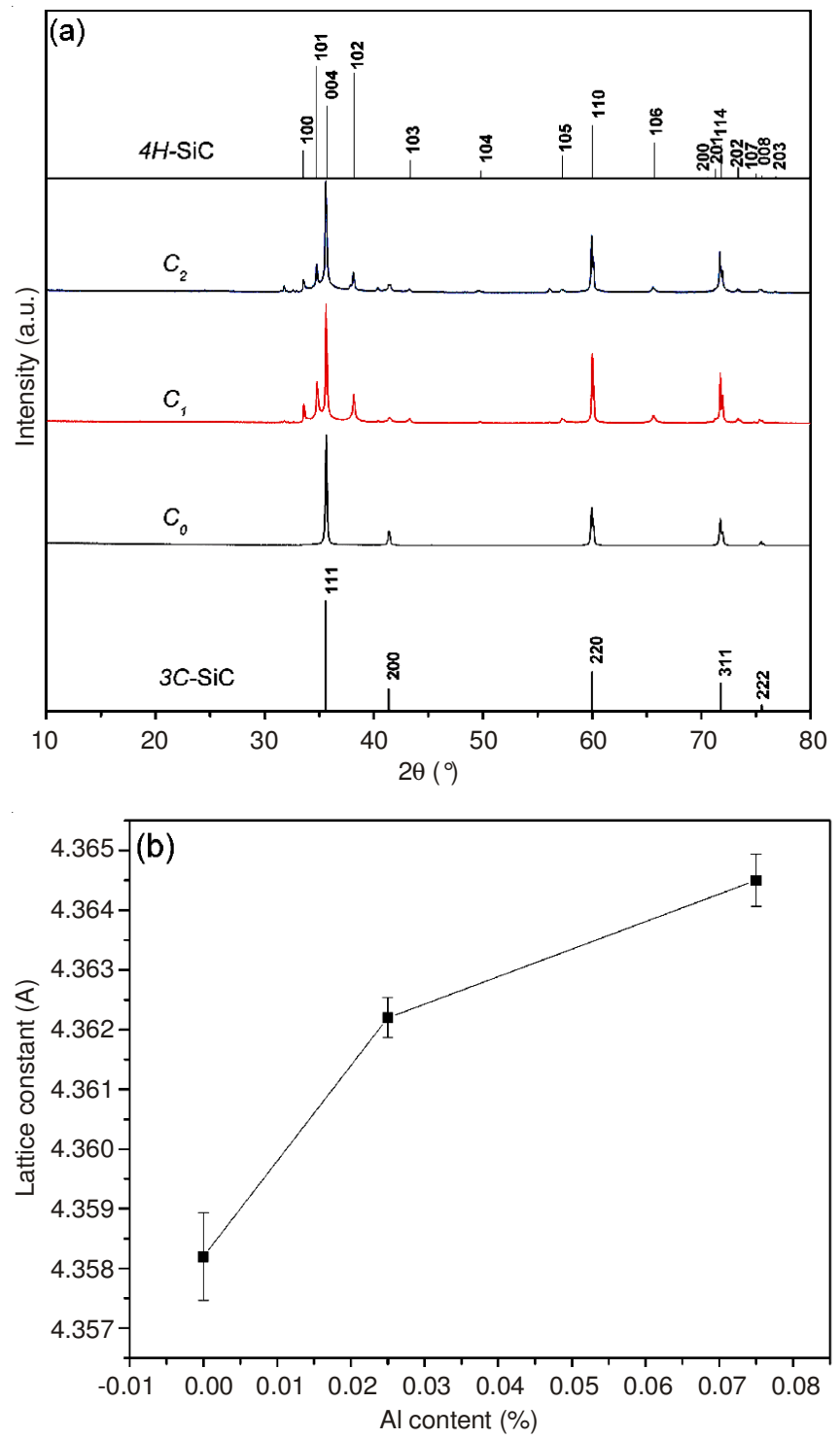

Fig. 1. (a) XRD chart of SiC samples with different Al-doped contents, (b) changes in $\mathrm{SiC}$ lattice constant with differing $\mathrm{Al}$ content

Fig. 1(b) shows the relationship between the $3 \mathrm{C}-\mathrm{SiC}$ lattice constant and varying $\mathrm{Al}$ content. As the $\mathrm{Al}$ content increases, the $3 \mathrm{C}-\mathrm{SiC}$ lattice constant also increases, which indicates that the $\mathrm{Al}$ atom enters the $\mathrm{SiC}$ lattice by replacing the $\mathrm{Si}$ atom and increasing from 4.353-4.355 $\mathrm{A}$. This shows that the $\mathrm{Al}$ atom enters intracell of $\mathrm{SiC}$ and forms a finite substitutional solid solution.

Characterization of morphology: Fig. 2(a) is a SEM picture of crystals without coping SiC. The morphology shows that the powder has equiaxed the grain and its particle size range is $0.5-1 \mu \mathrm{m}$. Fig. 2(b,c) show the microstructure of an 

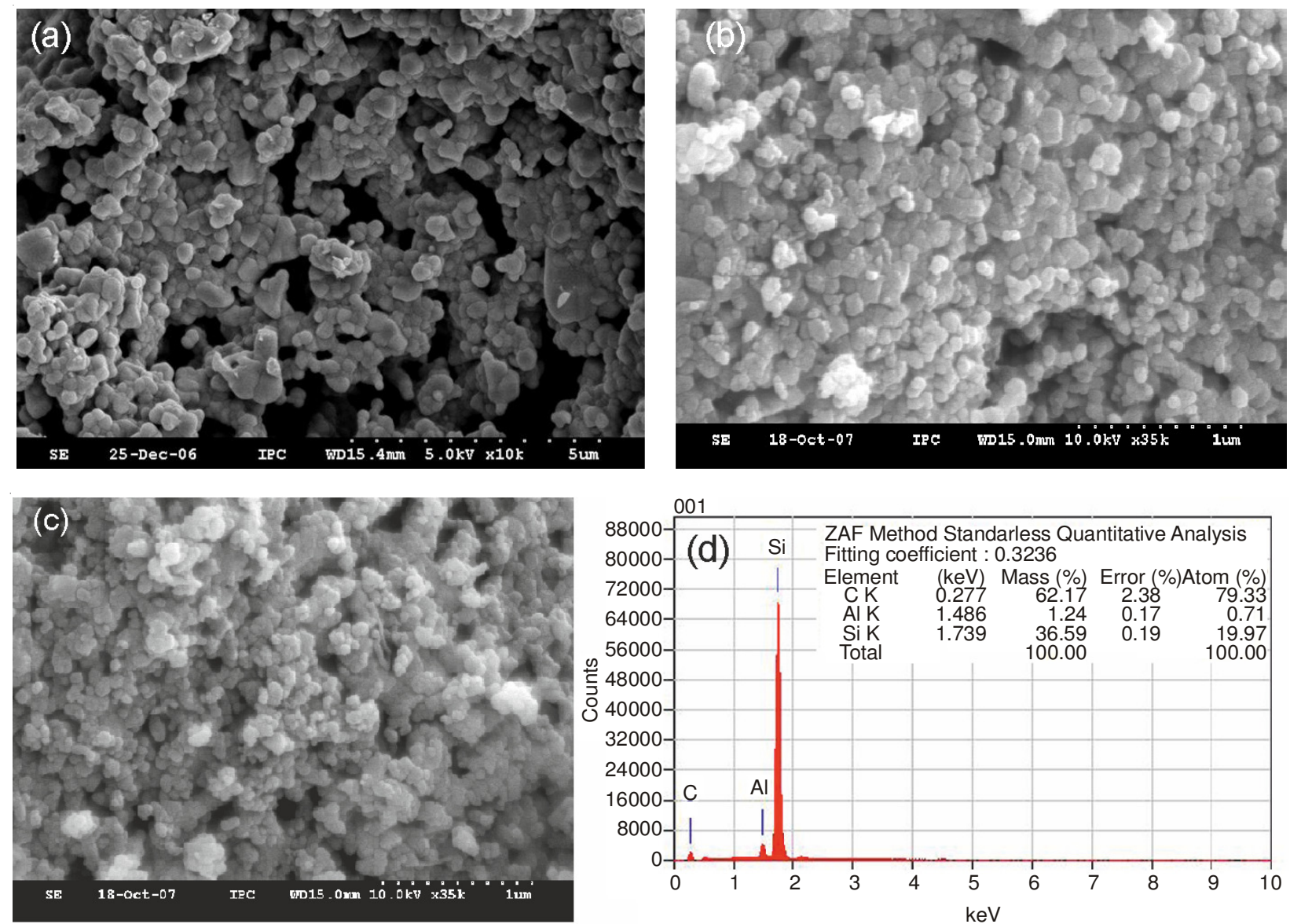

Fig. 2. (a) SEM pictures about crystals without coping, (b,c) SiC SEM pictures about Al-doped SiC powder, (d) An EDS chart about Al-doped SiC powder (under a voltage of $15 \mathrm{kV}$ )

Al-doped SiC crystal that also has equiaxial morphology and average grain diameter of 50-100 $\mathrm{nm}$. Fig 2(d) is an EDS chart of the Al-doped $\mathrm{SiC}$ powder. The chart shows that only $\mathrm{Al}, \mathrm{Si}$ and $\mathrm{C}$ exist in the composite powder.

Fig. 3 shows the TEM morphology of a single Al-doped $\mathrm{SiC}$ crystal, on which we can see clear lattice stripes. This implies that the composite $\mathrm{SiC}$ crystal has a favorable crystal form. In addition, various defects exist inside the crystal; more than likely they are planar defects that are common in $\mathrm{SiC}$ crystals or twin crystal defects. The foregoing forms indicate that the stacking series on the atom layer is destroyed in the process of SiC powder's normal crystal growth and many structural defects are introduced after $\mathrm{Al}$ coping enters the $\mathrm{SiC}$ crystals. We hypothesize that some of the $4 \mathrm{H}-\mathrm{SiC}$ phases in the foregoing XRD results are caused by stacking fault defects resulting from $\mathrm{Al}$ doping.

Infrared radiating performance of the coating: The degree of infrared emissivity is a key indicator of whether or not a material has good or bad infrared radiating performance. Fig. 4 shows the relationship between the emissivity of the prepared metal-matrix infrared radiating coating and the changes in wavelength. In accordance with the figure, the infrared emissivity of the coating sof $2.5-10 \mu \mathrm{m}$ is above 0.9 . Additionally, in the scope of 2.5-22.5 $\mu \mathrm{m}$, normal infrared emissivity is 0.89 and radiating capacity is strong. Thus, the coating may be applied to infrared baking and heating fields.

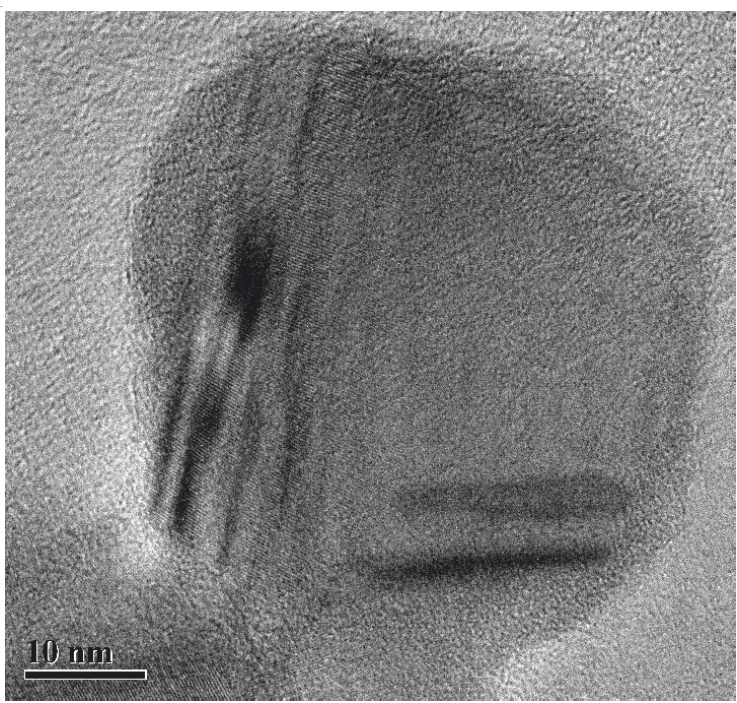

Fig. 3. TEM morphology of a single Al-doped $\mathrm{SiC}$ crystal in sample $\mathrm{C}_{3}$

Impacts of Al doping on the $\mathrm{SiC}$ powder's infrared radiating performance: The infrared radiation of materials is primarily a result of asymmetrical particle vibrations that produce changes in the dipole moment. A doping treatment is an important way of reducing materials' symmetry. Furthermore, the existence of impurities in the crystals destroy some parts of the periodic potential field. At some of these impurities, the electron energy state is different from other parts' energy 


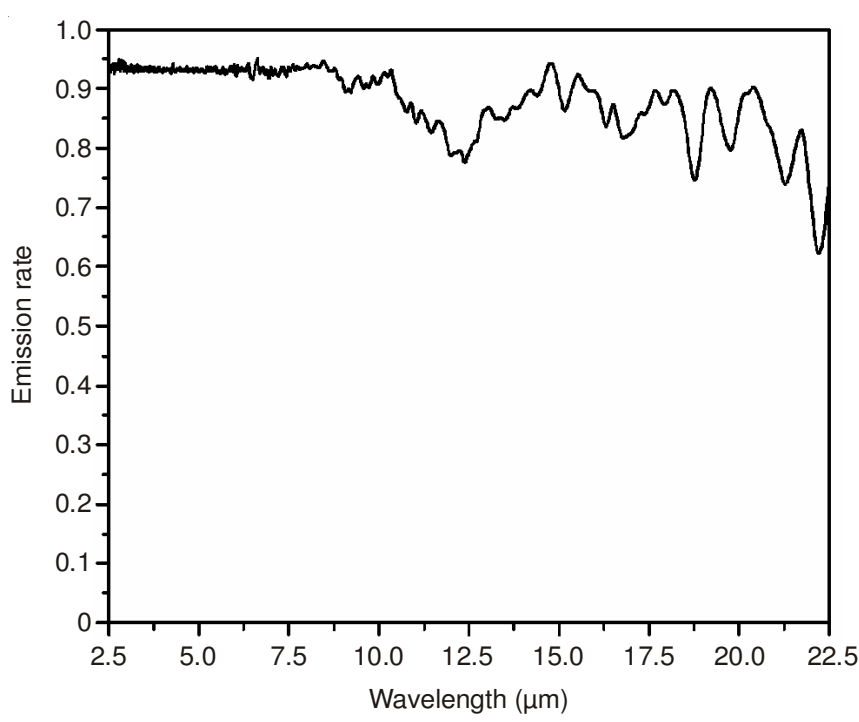

Fig. 4. A spectrum chart exhibiting the infrared emissivity of the infrared coating

states and the impurity energy level appears in the energy gaps of an electron forbidden band, which is convenient for electrons transitions and holes in the valence band as well as improves the infrared absorption process related to crystals and free carrier. Moreover, when atoms in the crystals are replaced by impurities, the crystal lattices suffer translation and their symmetry is destroyed. At some impurities-centered areas, their lattice constant and atomic mass are different from those of other parts. When both the lattice constant and reduced mass of local impurities areas are relatively small, the latticevibration spectral absorption waveband will move towards the infrared short wave in order to improve the near infrared spectrum (NIS) absorptive characteristics of crystals ${ }^{6}$. Moreover, there are various forms in which impurities get incorporated into crystals. Accordingly, all kinds of colour center absorption and crystal field absorption will be formed in the crystals. Thus, appropriating the coping for crystal materials in infrared radiating coating will effectively improve the infrared radiance and absorption performance of the infrared radiating coating. Through the process of $\mathrm{Al}$ coping for SiC crystals, the lattice constant increases, the lattice vibration's symmetry is reduced, the non-simple harmonic effect of the lattice polarity vibration is enhanced and the lattice vibration absorption is enhanced. The radiation band of phonon is connected to that of the electron transition so that a strong radiation band is formed in a wide wave band. Therefore, the material's infrared radiation characteristic is improved.

\section{Conclusion}

In this paper, combustion synthesis technology was used to prepare an $\mathrm{Al}$-doped $\mathrm{SiC}$ infrared ceramic powder material. Based on our results, $\mathrm{Al}$ doping may introduce many interior defects to $\mathrm{SiC}$ as well as cause local structural distortion of the SiC crystal so that the material's infrared radiation characteristic is greatly improved and its room-temperature full-wave band normal emissivity can reach up to 0.89 . It is expected that the composite Al-doped nanometer infrared radiating powder material will be widely applied to the infrared hearting fields.

\section{REFERENCES}

1. H. Takashima, K. Matsubara, Y. Nishimura and E. Kato, J. Japan. Ceram. Soc., 373, 90 (1982).

2. Y. Zhang, J.H. Gan and D.J. Wen, J. Infrared Technol., 54, 30 (2008).

3. Y.J. Cheng and L.G. He, J. Metallurgical Power, 55, 6 (2008).

4. Y. Zhang and D.J. Wen, J. Synth. Crys., 37, 341 (2008).

5. K. Yang, J. Yang, Z.M. Lin and J.T. Li Jiangtao, J. Inorg. Mater, 22, 263 (2007).

6. D.G. Ouyang, M.S. Zhou, Q.G. Zhang and K.W. Xiao, J. Steel Study, 39, 4 (1998). 